\title{
Anti-metastatic Effect of Short-term Postoperative Anticoagulation for Patients Undergoing Curative Resection of Colorectal Cancer
}

\author{
YUSUKE YAMAOKA ${ }^{1}$, MASATAKA IKEDA ${ }^{1}$, MASAKAZU IKENAGA $^{2}$, HIROTOMO MURAKAMI $^{1}$, \\ NAOTSUGU HARAGUCHI ${ }^{3}$, MASAKAZU MIYAKE ${ }^{1}$, KAZUYOSHI YAMAMOTO ${ }^{4}$, \\ TADAFUMI ASAOKA ${ }^{3}$, KAZUHIRO NISHIKAWA ${ }^{1}$, ATSUSHI MIYAMOTO ${ }^{1}$, \\ MICHIHIKO MIYAZAKI ${ }^{1}$, MOTOHIRO HIRAO ${ }^{1}$, SHOJI NAKAMORI ${ }^{1}$ and MITSUGU SEKIMOTO ${ }^{1}$ \\ ${ }^{1}$ Department of Surgery, National Hospital Organization, Osaka National Hospital, Osaka, Japan; \\ ${ }^{2}$ Department of Surgery, Higashiosaka City General Hospital, Higashiosaka, Osaka, Japan; \\ ${ }^{3}$ Department of Gastroenterological Surgery, Graduate School of Medicine, Osaka University, Suita, Japan; \\ ${ }^{4}$ Department of Gastroenterological Surgery, NTT West Osaka Hospital, Osaka, Japan
}

\begin{abstract}
Background: The purpose of this study was to examine the efficacy of anticoagulant fondaparinux postoperatively for preventing recurrence after curative resection of colorectal cancer with lymphnode metastasis. Patients and Methods: The records of 279 patients who underwent curative resection of colorectal cancer with lymphnode metastasis between 2006 and 2013 were reviewed. Patients were divided into two groups based on the type of prophylaxis for postoperative venous thromboembolism: the FPX group, treated with subcutaneous fondaparinux plus intermittent pneumatic compression; and the IPC group, treated with intermittent pneumatic compression alone. Recurrence-free survival was compared using propensity score matching. Results: In the propensity score-matched cohort, the 3-year recurrence-free survival rate was $74.9 \%$ and $74.4 \%$ in the FPX $(n=61)$ and IPC groups $(n=61)$, respectively $(p=0.830)$. Conclusion: Our results do not suggest that short-term postoperative anticoagulation as prophylaxis for venous thromboembolism prevents colorectal cancer recurrence after curative resection.
\end{abstract}

Patients undergoing surgery for colorectal cancer (CRC) are at high risk of venous thromboembolism (VTE) because of cancer-associated activation of the hemostatic system $(1,2)$.

Correspondence to: Masataka Ikeda, MD, Ph.D., Department of Surgery, National Hospital Organization Osaka National Hospital, 2-1-14 Hoenzaka, Chuo-ku, Osaka 540-0006, Japan. Tel: +81 669421331, Fax: +81 669463608, e-mail: mikeda@onh.go.jp

Key Words: Colorectal cancer, anticoagulation, fondaparinux, recurrence, anticancer effect, propensity score matching.
Postoperative anticoagulation therapy is recommended as VTE prophylaxis (3).

On the other hand, one experimental study demonstrated that surgical stress promotes cancer metastasis via postoperative hypercoagulability (4). Therefore, the perioperative period may be an optimal time to influence the development of metastatic disease using anticoagulation therapy (5). However, little is known about the effect of perioperative anticoagulation therapy on prognosis after cancer resection. This study was conducted using propensity score matching to determine the efficacy of postoperative fondaparinux (FPX) in preventing recurrence after curative resection of CRC with lymph-node metastasis, which has a high risk of recurrence.

\section{Materials and Methods}

Study population. The present study included 273 patients with primary CRC with pathologically diagnosed lymph-node metastasis who underwent curative (R0) resection between April 1, 2006 and March 31, 2013 at Osaka National Hospital. Patients who received neoadjuvant chemotherapy or preoperative radiotherapy, received postoperative unfractionated heparin (UFH) or low-molecular-weight heparin (LMWH), or underwent a concomitant surgical procedure for another type of cancer, such as gastrectomy, esophagectomy, hepatectomy, splenectomy, or pancreatectomy, were excluded.

Treatment. All patients underwent elective resection of CRC under general anesthesia and received intermittent pneumatic compression (IPC) from the beginning of anesthesia until they were fully ambulatory. Beginning in 2010, our Institutions adopted FPX, a synthetic selective inhibitor of factor Xa, for thromboprophylaxis after CRC surgery. The patients were divided into two groups. The FPX group was treated with IPC and subcutaneous FPX (1.5 or 2.5 $\mathrm{mg}$ ) once daily for 4 days or more. The IPC group was treated with 
IPC alone as a control. In principle, 5-fluorouracil-based adjuvant chemotherapy was administered to patients younger than 75 years of age without any severe comorbidities.

Recurrence-free survival (RFS) was compared between the two groups. RFS was defined as the time between curative resection and the first recurrence confirmed by pathology or progressively increasing tumor size in imaging studies.

Statistical analysis. We performed propensity score matching to reduce the possibility of selection bias and to adjust for significant differences in baseline characteristics between patients in the FPX and IPC groups. To estimate the propensity score, logistic regression was performed with the following 10 variables: gender; age; American Society of Anesthesiologists (ASA) grade: tumor location; pathological $\mathrm{T}$ category; pathologic $\mathrm{N}$ category; histological type; preoperative serum carcinoembryonic antigen (CEA) level; type of surgery (laparoscopic or open); and adjuvant chemotherapy. $\mathrm{T}$ and $\mathrm{N}$ categories were based on the seventh version of the Union for International Cancer Control TNM classification system (6). Each patient in the FPX group was matched to a patient in the IPC group based on these variables. Oneto-one pair matching was performed without replacement, and propensity scores were matched with a caliper of 0.001 .

We compared the clinical characteristics of the patients, followup duration, and RFS in the two groups. In the propensity scorematched cohort, Cox proportional hazards regression was used to identify predictors of RFS. Continuous variables were expressed as medians and compared using Student's $t$-test. RFS was determined from Kaplan-Meier curves and compared using the log-rank test. Categorical variables were compared using the $\chi^{2}$ test or Fisher's exact test in the full cohort. They were compared using McNemar's test in the propensity score-matched cohort. All statistical analyses were performed using JMP software, version 11.0 (SAS Institute Inc., Cary, NC, USA) and the statistical program R (http://www.rproject.org/), with advice from an experienced statistician. A $p$-value of less than 0.05 was considered statistically significant.

\section{Results}

Baseline variables of the patients in the FPX $(\mathrm{n}=118)$ and IPC $(n=161)$ groups are shown in Table I. No statistically significant differences were observed in gender, age, ASA grade, tumor location, pathological $\mathrm{T}$ category, pathological $\mathrm{N}$ category, histological type, preoperative CEA level, or the proportion of patients receiving adjuvant chemotherapy. A higher proportion of patients in the FPX group (60\%) underwent laparoscopic surgery compared to the IPC group $(29 \%)(p<0.001)$. After propensity score matching, there were no significant differences in any of the baseline variables between the FPX $(n=61)$ and IPC $(n=61)$ groups. The median duration of FPX therapy was 4 days (range $=1-5$ days).

For the full cohort, the 3-year RFS rate was $68.3 \%$ in the FPX group and $72.7 \%$ in the IPC group (Figure 1a). The median follow-up duration was 47.8 months in the FPX group and 61.2 months in the IPC group $(p<0.001)$. In the propensity score-matched cohort, the 3-year RFS rate was $74.9 \%$ in the FPX group and $74.4 \%$ in the IPC group (Figure 1b). The median follow-up duration was longer in the FPX group (50.4 months) than in the IPC group (61.2 months) $(p<0.001)$. In both cohorts, there were no significant differences in RFS between the two groups.

Predictors of RFS in propensity score-matched cohort in the univariate and multivariate analyses are shown in Table II. Among the 11 variables investigated, multivariate analysis identified only pathological $\mathrm{T}$ category of $\mathrm{T} 4 \mathrm{a}$ or $\mathrm{T} 4 \mathrm{~b}$ (hazard ratio $=4.64,95 \%$ confidence interval $=1.55-13.9$; $p=0.006$ ) as an independent predictor of poorer RFS.

\section{Discussion}

In patients with cancer, an activated coagulation system can facilitate tumor progression and metastasis via several mechanisms, including tumor cell spreading, direct stimulation of tumor growth and angiogenesis by platelets, inhibition of natural killer cells, and recruitment of macrophages $(7,8)$. LWMH was reported to have a favorable influence on survival in patients with advanced cancer as a result of its anticancer effect $(9,10)$. On the other hand, surgery activates platelets and the extrinsic coagulation pathways, leading to formation of thrombin and fibrin clots. Patients undergoing surgery are in a hypercoagulable state (11-13). Seth et al. demonstrated that surgical stress promotes cancer metastasis via activated platelets and fibrin clots, which impaired the ability of natural killer cells to clear tumor cells in an experimental study (4). Therefore, perioperative anticoagulation therapy has the potential to prevent tumor recurrence as well as VTE.

FPX is a synthetic selective inhibitor of factor Xa. Its safety and efficacy in VTE prophylaxis after CRC resection have been reported (14). Battinelli et al. demonstrated that FPX and LMWH exert anticancer effects by suppressing tumor cell-mediated release of platelet angiogenic proteins and diminishing the platelet angiogenic response (15). In order to examine the anti-metastatic effect of postoperative FPX given as VTE prophylaxis, we examined patients undergoing curative resection of CRC with lymphnode metastasis who were at higher risk of recurrence. However, there were no significant differences in RFS between the FPX and IPC groups when considering the full and propensity score-matched cohorts. Only pathological T4a or T4b status was, not surprisingly, identified as an independent predictor of poorer RFS in the multivariate analysis.

To the best of our knowledge, there have been only three clinical studies evaluating the anticancer effect of perioperative anticoagulation therapy (16-18). Kingston et al. showed that perioperative administration of UFH results in significant improvements in both 5-year overall and disease-free survival in patients with stage III CRC undergoing curative resection in a post hoc analysis of a randomized trial evaluating adjuvant razoxane (16). A 
Table I. Clinical characteristics of the study patients.

\begin{tabular}{|c|c|c|c|c|c|c|}
\hline & \multicolumn{3}{|c|}{ Full cohort $(\mathrm{n}=279), \mathrm{n}(\%)$} & \multicolumn{3}{|c|}{ Propensity score-matched cohort $(\mathrm{n}=122), \mathrm{n}(\%)$} \\
\hline & FPX $(n=118)$ & $\operatorname{IPC}(n=161)$ & $p$-Value* & $\operatorname{FPX}(\mathrm{n}=61)$ & $\operatorname{IPC}(n=61)$ & $p$-Value** \\
\hline Gender & & & 0.49 & & & 0.763 \\
\hline Male & $64(54.2)$ & $94(58.2)$ & & $36(59.0)$ & $37(60.7)$ & \\
\hline Female & $54(45.8)$ & $67(41.6)$ & & $25(41.0)$ & $24(39.3)$ & \\
\hline Age & & & 0.847 & & & 0.248 \\
\hline$<75$ Years & $86(72.9)$ & $119(73.9)$ & & $47(77.0)$ & $43(70.5)$ & \\
\hline$\geq 75$ Years & $32(27.1)$ & $42(26.1)$ & & $14(23.0)$ & $18(29.5)$ & \\
\hline ASA grade & & & 0.894 & & & 0.317 \\
\hline $\mathrm{I}, \mathrm{II}$ & $114(96.6)$ & $156(96.9)$ & & $61(100)$ & $60(98.4)$ & \\
\hline III & $4(3.4)$ & $5(3.1)$ & & $0(0)$ & $1(1.6)$ & \\
\hline Tumor location & & & 0.415 & & & 1 \\
\hline Colon & $71(60.2)$ & $89(55.3)$ & & $36(59.0)$ & $36(59.0)$ & \\
\hline Rectum & $47(39.8)$ & $72(44.7)$ & & $25(41.0)$ & $25(41.0)$ & \\
\hline Pathological T category & & & 0.532 & & & 0.655 \\
\hline $\mathrm{T} 1,2,3$ & $94(79.7)$ & $133(82.6)$ & & $54(88.5)$ & $55(90.2)$ & \\
\hline $\mathrm{T} 4 \mathrm{a}, \mathrm{T} 4 \mathrm{~b}$ & $24(20.3)$ & $28(17.4)$ & & $7(11.5)$ & $6(9.8)$ & \\
\hline Pathological N category & & & 0.939 & & & 0.763 \\
\hline $\mathrm{N} 1$ & $86(72.9)$ & $118(73.3)$ & & $50(82.0)$ & $51(83.6)$ & \\
\hline $\mathrm{N} 2$ & $32(27.1)$ & $43(26.7)$ & & $11(18.0)$ & $10(16.4)$ & \\
\hline Histological type & & & 0.101 & & & 0.317 \\
\hline Well, moderate & $112(94.9)$ & $144(89.4)$ & & $59(96.7)$ & $58(95.1)$ & \\
\hline Poor, mucinous & $6(5.1)$ & $17(10.6)$ & & $2(3.3)$ & $3(4.9)$ & \\
\hline Preoperative serum CEA & & & 0.841 & & & 0.491 \\
\hline$<5 \mathrm{ng} / \mathrm{ml}$ & $63(53.4)$ & $84(52.2)$ & & $34(55.7)$ & $37(60.7)$ & \\
\hline$\geq 5 \mathrm{ng} / \mathrm{ml}$ & $55(46.6)$ & $77(47.8)$ & & $27(44.3)$ & $24(39.3)$ & \\
\hline Operative procedure type & & & $<0.001$ & & & 1 \\
\hline Open & $47(39.8)$ & $114(70.8)$ & & $34(55.7)$ & $34(55.7)$ & \\
\hline Laparoscopic & $71(60.2)$ & $47(29.2)$ & & $27(44.3)$ & $27(44.3)$ & \\
\hline Adjuvant chemotherapy & & & 0.365 & & & 0.655 \\
\hline Yes & $28(23.7)$ & $46(28.6)$ & & $11(18.0)$ & $10(16.4)$ & \\
\hline No & $90(76.3)$ & $115(71.4)$ & & $50(82.0)$ & $51(83.6)$ & \\
\hline Included oxaliplatin & $8(8.9)$ & $9(7.8)$ & & $4(8.0)$ & $2(3.9)$ & \\
\hline
\end{tabular}

FPX, Group receiving fondaparinux and intermittent pneumatic compression; IPC, group receiving intermittent pneumatic compression; ASA, American Society of Anesthesiologists; Well, well-differentiated adenocarcinoma; Moderate, moderately differentiated adenocarcinoma; Poor, poorly differentiated adenocarcinoma; Mucinous, mucinous adenocarcinoma; CEA, carcinoembryonic antigen. * $\chi 2$ test or Fisher's exact test. **McNemar's test.

subgroup analysis of a randomized trial revealed that patients receiving perioperative LMWH for 7 days after surgery for pelvic gynecological cancer had better overall survival than those who received perioperative UFH (17). Currently, a large multicenter randomized controlled trial evaluating the anticancer effect of perioperative LMWH for 8 weeks after surgery in patients with resectable CRC is ongoing (18) after a pilot study had demonstrated its feasibility (5). Unlike those studies, administration of FPX in our study began postoperatively, not preoperatively. The median duration of FPX therapy (4 days) was shorter than in other studies. These factors might account for why we did not observe differences in RFS between the FPX and IPC groups. Several experimental studies have demonstrated that UFH and LWMH have anti-metastatic effects, not as a result of their anticoagulant activity, but by inhibition of selectins.
Selectins contribute to metastasis by mediating interactions among tumor cells, platelets, leukocytes and endothelial cells (19-21). However, an experimental study showed that FPX does not inhibit selectins because of its different structure in binding them (22). FPX is a pentasaccharide that binds to anti-thrombin and specifically inhibits factor $\mathrm{Xa}$, not thrombin (23). It may have no antitumor effect because it has very specific anticoagulant activities.

This study has several limitations. Firstly, this was a retrospective study, hence the primary end-point, RFS, could not be defined in advance. Secondly, patients were compared over two time periods. Our Institution adopted FPX in 2010. The number of patients receiving FPX gradually increased until FPX was routinely used in 2011. Thirdly, overall survival was not evaluated because the standard chemotherapy for recurrent CRC changed during our study period $(24,25)$. 
a

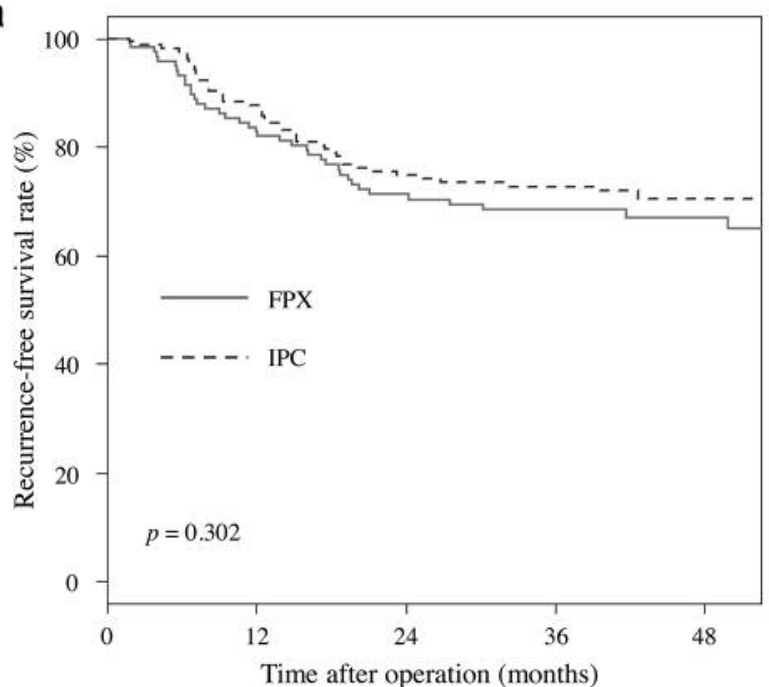

No. at risk

FPX 118

IPC 161

97

135
79

109 b

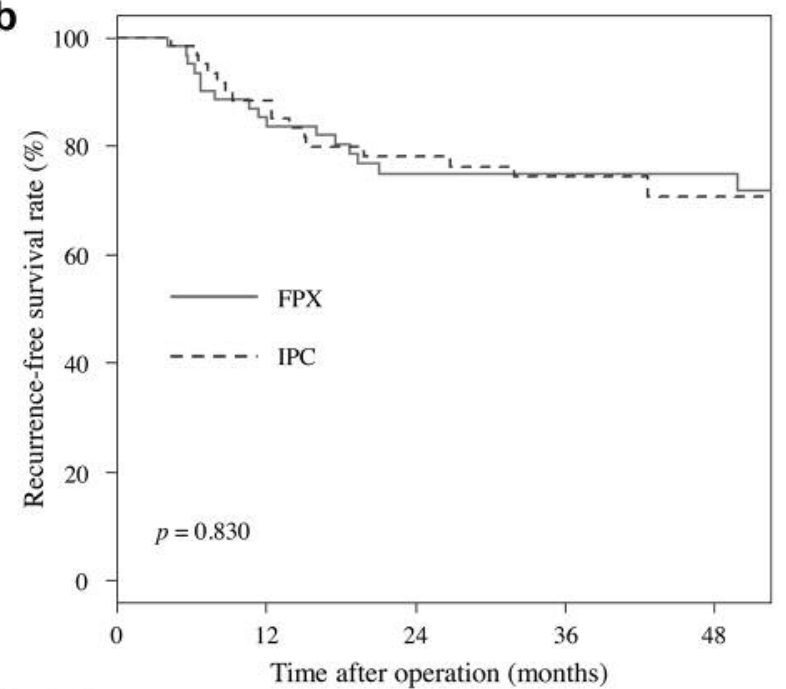

No. at risk

$\begin{array}{llllll}\text { FPX } & 61 & 53 & 43 & 43 & 43 \\ \text { IPC } & 61 & 54 & 45 & 42 & 38\end{array}$

Figure 1. Recurrence-free survival curves for the group receiving fondaparinux and intermittent pneumatic compression (FPX) and the group receiving intermittent pneumatic compression alone (IPC) considering the full (a) and propensity score-matched (b) cohorts. The 3-year recurrencefree survival rates were $68.39 \%$ and $72.7 \%$, respectively, in the full cohort and $74.9 \%$ and $74.4 \%$, respectively, in the matched cohort.

Table II. Predictors of recurrence-free survival in the propensity score-matched cohort $(n=122)$.

\begin{tabular}{|c|c|c|c|c|}
\hline & \multicolumn{2}{|l|}{ Univariate analysis } & \multicolumn{2}{|l|}{ Multivariate analysis } \\
\hline & Hazard ratio ( $95 \%$ confidence interval) & $p$-Value & Hazard ratio ( $95 \%$ confidence interval) & $p$-Value \\
\hline \multicolumn{5}{|l|}{ Gender } \\
\hline Male/female & $1.503(0.733-3.084)$ & 0.266 & $1.361(0.641-2.888)$ & 0.423 \\
\hline \multicolumn{5}{|l|}{ Age } \\
\hline$<75$ Years $/ \geq 75$ years & $0.822(0.393-1.719)$ & 0.602 & $0.778(0.309-1.958)$ & 0.593 \\
\hline \multicolumn{5}{|l|}{ ASA grade } \\
\hline III/I, II & NA & 0.998 & NA & 0.997 \\
\hline \multicolumn{5}{|l|}{ Tumor location } \\
\hline Rectum/colon & $1.658(0.846-3.253)$ & 0.141 & $2.217(0.935-5.258)$ & 0.071 \\
\hline \multicolumn{5}{|l|}{ Pathological $\mathrm{T}$ category } \\
\hline $\mathrm{T} 4 \mathrm{a}, 4 \mathrm{~b} / \mathrm{T} 1,2,3$ & $3.823(1.648-8.869)$ & 0.002 & $4.642(1.551-13.892)$ & 0.006 \\
\hline \multicolumn{5}{|l|}{ Pathological N category } \\
\hline $\mathrm{N} 2 / \mathrm{N} 1$ & $1.179(0.513-2.708)$ & 0.698 & $0.970(0.377-2.498)$ & 0.950 \\
\hline \multicolumn{5}{|l|}{ Histological type } \\
\hline Poor, mucinous/well, moderate & $0.844(0.115-6.176)$ & 0.867 & $0.593(0.072-4.903)$ & 0.628 \\
\hline \multicolumn{5}{|l|}{ Preoperative serum CEA } \\
\hline$\geq 5 \mathrm{ng} / \mathrm{ml} /<5 \mathrm{ng} / \mathrm{ml}$ & $2.227(1.124-4.413)$ & 0.022 & $1.425(0.658-3.084)$ & 0.369 \\
\hline \multicolumn{5}{|l|}{ Operative procedure } \\
\hline Open surgery/laparoscopic surgery & $1.959(0.952-4.021)$ & 0.067 & $1.509(0.673-3.385)$ & 0.318 \\
\hline \multicolumn{5}{|l|}{ Adjuvant chemotherapy } \\
\hline Present/absent & $0.829(0.343-2.004)$ & 0.677 & $0.940(0.299-2.959)$ & 0.916 \\
\hline \multicolumn{5}{|l|}{ Postoperative anticoagulation therapy } \\
\hline $\mathrm{FPX} /$ none & $0.929(0.472-1.829)$ & 0.832 & $1.009(0.508-2.003)$ & 0.980 \\
\hline
\end{tabular}

ASA, American Society of Anesthesiologists; Well, well-differentiated adenocarcinoma; Moderate, moderately differentiated adenocarcinoma; Poor, poorly differentiated adenocarcinoma; Mucinous, mucinous adenocarcinoma; CEA, carcinoembryonic antigen; FX, fondaparinux; NA, not applicable. 
Our results do not suggest that short-term postoperative use of FPX as VTE prophylaxis prevents CRC recurrence after curative resection. The retrospective nature of this study performed in a single Institution and the relatively small size of the study population warrant further studies on this issue.

\section{References}

1 Bergqvist D: Venous thromboembolism: a review of risk and prevention in colorectal surgery patients. Dis Colon Rectum 49: 1620-1628, 2006.

2 Iversen LH and Thorlacius-Ussing O: Relationship of coagulation test abnormalities to tumour burden and postoperative DVT in resected colorectal cancer. Thromb Haemost 87: 402-408, 2002.

3 Gould MK, Garcia DA, Wren SM, Karanicolas PJ, Arcelus JI, Heit JA and Samama CM; American College of Chest Physicians: Prevention of VTE in nonorthopedic surgical patients: Antithrombotic Therapy and Prevention of Thrombosis, 9th ed: American College of Chest Physicians Evidence-Based Clinical Practice Guidelines. Chest 141: e227S-277S, 2012.

4 Seth R, Tai LH, Falls T, de Souza CT, Bell JC, Carrier M, Atkins $\mathrm{H}$, Boushey R and Auer RA: Surgical stress promotes the development of cancer metastases by a coagulation-dependent mechanism involving natural killer cells in a murine model. Ann Surg 258: 158-168, 2013.

5 Auer R, Scheer A, Wells PS, Boushey R, Asmis T, Jonker D and Carrier M: The use of extended perioperative low molecular weight heparin (tinzaparin) to improve disease-free survival following surgical resection of colon cancer: a pilot randomized controlled trial. Blood Coagul Fibrinolysis 22: 760-762, 2011.

6 Sobin LH, Brierley J: Colon and Rectum. In: Sobin LH, Gospodarowicz MK, Wittekind Ch (eds.). International Union Against Cancer (UICC) TNM Classification of Malignant Tumors. 7th ed. Wiley-Blackwell, Oxford, UK, pp. 100-105, 2009.

7 Gil-Bernabé AM, Ferjancic S, Tlalka M, Zhao L, Allen PD, Im JH, Watson K, Hill SA, Amirkhosravi A, Francis JL, Pollard JW, Ruf W and Muschel RJ: Recruitment of monocytes/macrophages by tissue factor-mediated coagulation is essential for metastatic cell survival and premetastatic niche establishment in mice. Blood 119: 3164-3175, 2012.

8 Gil-Bernabé AM, Lucotti S and Muschel RJ: Coagulation and metastasis: What does the experimental literature tell us? Br J Haematol 162: 433-441, 2013.

9 Kakkar AK, Levine MN, Kadziola Z, Lemoine NR, Low V, Patel HK, Rustin G, Thomas M, Quigley M and Williamson RC: Lowmolecular-weight heparin, therapy with dalteparin, and survival in advanced cancer: the Fragmin Advanced Malignancy Outcome study (FAMOUS). J Clin Oncol 22: 1944-1948, 2004.

10 Klerk CP, Smorenburg SM, Otten HM, Lensing AW, Prins MH, Piovella F, Prandoni P, Bos MM, Richel DJ, van Tienhoven G and Büller HR: The effect of low-molecular-weight heparin on survival in patients with advanced malignancy. J Clin Oncol 23: 2130-2135, 2005

11 Xu WF, Andersen H, Whitmore TE, Presnell SR, Yee DP, Ching A, Gilbert T, Davie EW and Foster DC: Cloning and characterization of human protease-activated receptor 4. Proc Natl Acad Sci USA 95: 6642-6646, 1998.

12 Mackman N, Tilley RE and Key NS: Role of the extrinsic pathway of blood coagulation in hemostasis and thrombosis. Arterioscler Thromb Vasc Biol 27: 1687-1693, 2007.
13 McCrath DJ, Cerboni E, Frumento RJ, Hirsh AL and BennettGuerrero E: Thromboelastography maximum amplitude predicts postoperative thrombotic complications including myocardial infarction. Anesth Analg 100: 1576-1583, 2005.

14 Yamaoka Y, Ikeda M, Ikenaga M, Haraguchi N, Miyake M and Sekimoto M: Safety and efficacy of fondaparinux for prophylaxis of venous thromboembolism after colorectal cancer resection: a propensity score-matched analysis. Dig Surg 32: 190-195, 2015.

15 Battinelli EM, Markens BA, Kulenthirarajan RA, Machlus KR, Flaumenhaft R and Italiano JE Jr.: Anticoagulation inhibits tumor cell-mediated release of platelet angiogenic proteins and diminishes platelet angiogenic response. Blood 123: 101-112, 2014.

16 Kingston RD, Fielding JW and Palmer MK: Perioperative heparin: a possible adjuvant to surgery in colo-rectal cancer? Int J Colorectal Dis 8: 111-115, 1993.

17 von Tempelhoff GF, Harenberg J, Niemann F, Hommel G, Kirkpatrick CJ and Heilmann L: Effect of low-molecular-weight heparin (Certoparin) versus unfractionated heparin on cancer survival following breast and pelvic cancer surgery: A prospective randomized double-blind trial. Int J Oncol 16: 815-824, 2000.

$18 \mathrm{https} / / /$ clinicaltrials.gov/ct2/show/record/NCT01455831

19 Borsig L: Antimetastatic activities of modified heparins: selectin inhibition by heparin attenuates metastasis. Semin Thromb Hemost 33: 540-546, 2007.

20 Stevenson JL, Varki A and Borsig L: Heparin attenuates metastasis mainly due to inhibition of P- and L-selectin, but nonanticoagulant heparins can have additional effects. Thromb Res 120: S107-111, 2007.

21 Borsig L: Antimetastatic activities of heparins and modified heparins. Experimental evidence. Thromb Res 125: S66-71, 2010.

22 Stevenson JL, Choi SH and Varki A: Differential metastasis inhibition by clinically relevant levels of heparins - correlation with selectin inhibition, not antithrombotic activity. Clin Cancer Res 11: 7003-7011, 2005.

23 Bauer KA: New anticoagulants: anti IIa vs. anti Xa -Is one better? J Thromb Thrombolysis 21: 67-72, 2006.

24 Watanabe T, Itabashi M, Shimada Y, Tanaka S, Ito Y, Ajioka Y, Hamaguchi T, Hyodo I, Igarashi M, Ishida H, Ishiguro M, Kanemitsu Y, Kokudo N, Muro K, Ochiai A, Oguchi M, Ohkura Y, Saito Y, Sakai Y, Ueno H, Yoshino T, Fujimori T, Koinuma N, Morita T, Nishimura G, Sakata Y, Takahashi K, Takiuchi H, Tsuruta O, Yamaguchi T, Yoshida M, Yamaguchi N, Kotake K and Sugihara K; Japanese Society for Cancer of the Colon and Rectum: Japanese Society for Cancer of the Colon and Rectum (JSCCR) guidelines 2010 for the treatment of colorectal cancer. Int J Clin Oncol 17: 1-29, 2012.

25 Watanabe T, Itabashi M, Shimada Y, Tanaka S, Ito Y, Ajioka Y, Hamaguchi $\mathrm{T}$, Hyodo I, Igarashi $\mathrm{M}$, Ishida $\mathrm{H}$, Ishihara $\mathrm{S}$, Ishiguro M, Kanemitsu Y, Kokudo N, Muro K, Ochiai A, Oguchi M, Ohkura Y, Saito Y, Sakai Y, Ueno H, Yoshino T, Boku N, Fujimori T, Koinuma N, Morita T, Nishimura G, Sakata Y, Takahashi K, Tsuruta O, Yamaguchi T, Yoshida M, Yamaguchi N, Kotake K and Sugihara K; Japanese Society for Cancer of the Colon and Rectum: Japanese Society for Cancer of the Colon and Rectum (JSCCR) Guidelines 2014 for treatment of colorectal cancer. Int J Clin Oncol 20:207-239, 2015.

Received August 20, 2016

Revised September 12, 2016

Accepted September 15, 2016 